\title{
Attack/display as a reinforcer in Betta splendens
}

\author{
KENNETH B. MELVIN \\ University of Alabama, University, Alabama
}

\begin{abstract}
Nine of 10 bettas learned to swim across a hurdle to display to and attack a conspecific. Crossing responses were maintained until the target fish exhibited a submissive display; then crossing quickly ceased. Relearning and extinction were also shown.
\end{abstract}

A common preparation for the study of species-typical aggression is the male Siamese fighting fish (Betta splendens). The sight of another male betta releases in the fish a species-typical display, and fighting follows. Aggressive displays to mirror images have served as reinforcers for bettas in a number of studies (e.g., Melvin \& Anson, 1969; Thompson, 1963).

Although display has been shown to be reinforcing, a combination of display and actual fighting may have different effects. Given that actual fighting may lead to considerable stress and possible injury, it may differ in its reinforcing effects from display alone. The present study examines the effectiveness of a display and a fight as reinforcers for an instrumental response in bettas. The effects of submissive displays on the instrumental response were also examined.

\section{METHOD}

\section{Subjects}

The subjects were 10 male "show" bettas $4-5 \mathrm{~cm}$ in length. Fourteen similar bettas served as "target" fish. Fish were maintained in individual, visually isolated containers at a temperature of $80^{\circ} \pm 1^{\circ} \mathrm{F}$ and fed a daily diet of Tetramin.

\begin{abstract}
Apparatus
The apparatus consisted of a standard $25 \times 30 \times 15 \mathrm{~cm}$ aquarium, bisected by a black plexiglass partition $6.5 \mathrm{~cm}$ high. A guillotine door of black plexiglass was positioned on top of this partition. When the door was raised, a space $.5 \mathrm{~cm}$ between it and the partition was exposed. Water level was maintained $.6-.8 \mathrm{~cm}$ above the partition, making the response somewhat difficult (i.e., a fish usually turned on its side to cross). Water temperature in the apparatus was $80^{\circ} \pm 1^{\circ} \mathrm{F}$.
\end{abstract}

\section{Procedure}

Prior to Trial 1, two fish were habituated to the tank by being placed for $180 \mathrm{sec}$ on respective sides of the tank with the door lowered. During a trial, the door was raised, and a microswitch started a clock. As soon as a betta's caudal fin cleared the partition, the door was lowered, and crossing latency was recorded. The latency limit for crossing over was $180 \mathrm{sec}$; if no response occurred by this time, the door was lowered. If a fish crossed over, the fish were allowed to fight. The initiation of fighting was defined as the first bite. If fighting ensued, the fish were separated after approximately $10-15 \mathrm{sec}$.

We separated the fish by netting one fish and placing it in the other side of the tank with the door lowered. Possible negative effects of net-

I wish to express my appreciation for the capable technical assistance of Diana S. Reddel and Michael J. Naughton. My mailing address is: Department of Psychology, The University of Alabama, Box 2968, University, AL 35486. ting were controlled by alternating the order of fish netted. Once the fish were separated, the intertrial interval of $30 \mathrm{sec}$ began.

In most cases, one fish learned to cross first, continued crossing, and was designated the "subject." The other betta was designated the "target" fish. However, occasionally a target fish would cross, or the first fish to cross would not become the predominant crosser. In the latter case, the predominant crosser would be considered the subject. If a target fish became submissive, a new target fish was used on the following day. Latencies were not counted if a target fish crossed the partition. This procedure led to a variation in the number of trials per session, (14-24 trials). Also two paired fish, S6 and S7, each crossed an equivalent number of times, so both fish were considered subjects.

\section{RESULTS}

In the original design of this experiment, a constant number of acquisition trials were to be given, followed by extinction trials. An unpredicted finding ruined the neatness of the design but led to more interesting results. After about 8-12 fights, the target fish usually exhibited the submissive display (folding its fins, turning pale, and sinking to the bottom). Following this action, the subject betta quickly ceased crossing (extinguished?). Thus, curves are plotted for individual subjects.

Figure 1 illustrates this phenomenon for Subject 2 on Days 1 and 2. The submissive displays occurred during Block 6. Subject 2 also exhibited learning since latency

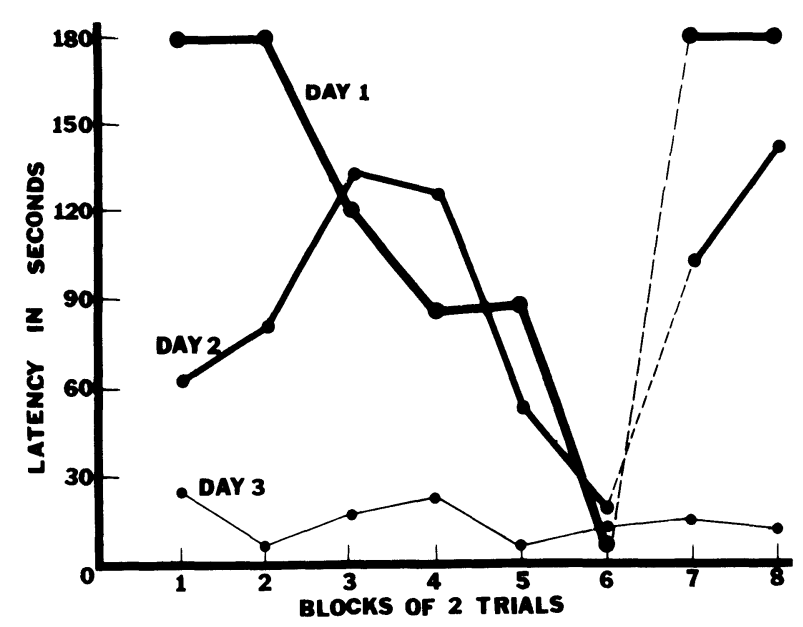

Figure 1. Median crossing latency (sec) for S2 over blocks of two trials on Days 1, 2, and 3. The dotted line is inserted here and on all further graphs following submissive display on the part of the target betta. 
decreased over Blocks 1-6. Relearning is shown by the reduction in latency across Days 1-3.

Similar results are shown for Subject 5 in Figure 2, except only one of the target fish became submissive (Day 1). Data for Subject 23 are quite similar to Subject 5 and thus are not graphed.

Figure 3 presents the results for Subject 16. Again, learning and relearning are evident. Submissive displaying began on Trial 9, and the following extinction was slightly more gradual.

Figure 4 presents data for three fish. Subject 9 exhibited learning, followed by rapid extinction after the submissive display. Subjects 6 and 7 were an evenly matched pair and both fish quickly learned to cross. Of 20 trials, each fish crossed 10 times. The number of bites and pattern of crossing were also equivalent.

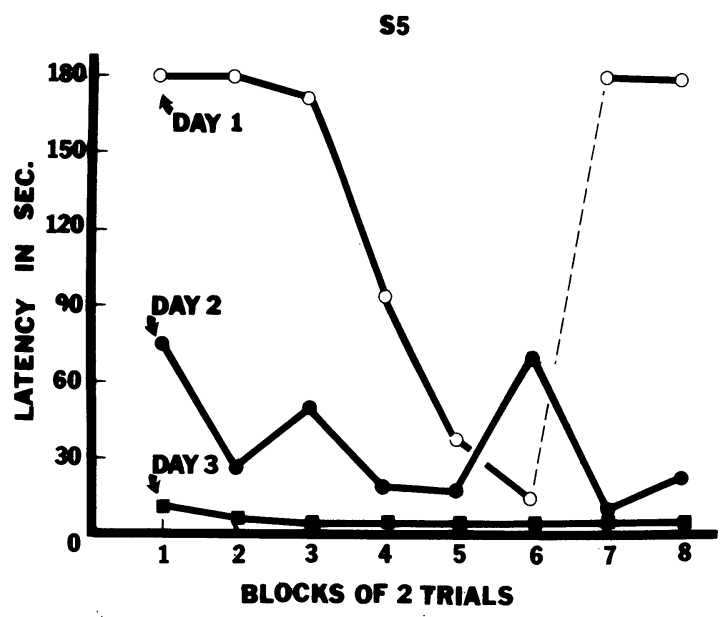

Figure 2. Median crossing latency (sec) for S5 over blocks of two trials on Days 1, 2, and 3.

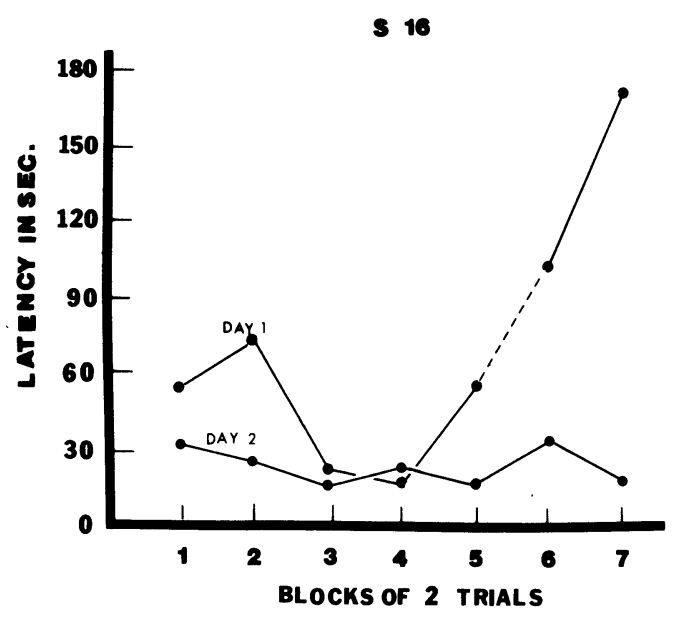

Figure 3. Median crossing latency (sec) for S16 over blocks of two trials on Days 1 and 2.

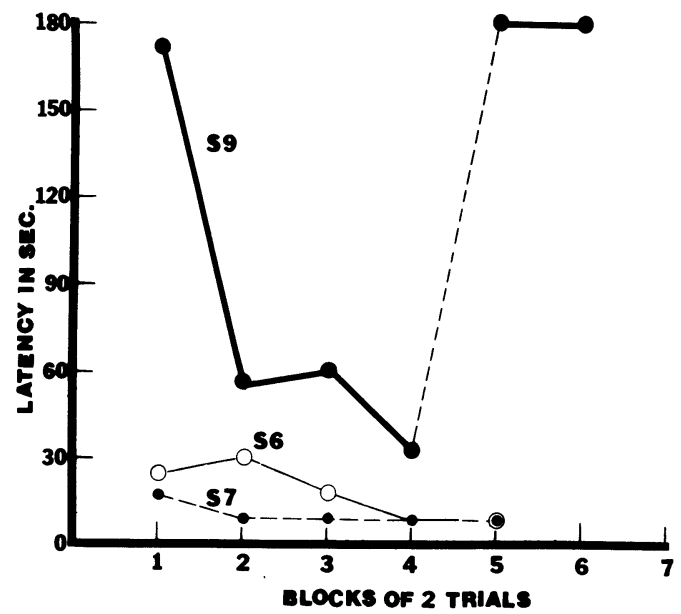

Figure 4. Median crossing latency (sec) for S9, S6, and S7 over blocks of two trials on Day 1 . The latter two fish were evenly matched antagonists, and both exhibited learning when paired during this session.

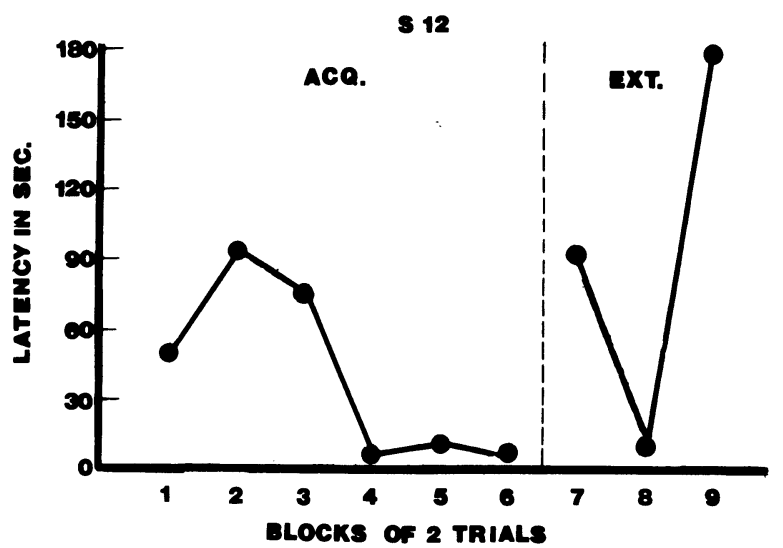

Figure 5. Median crossing latency (sec) for S12 over blocks of two trials on Day 1. Blocks 7, 8, and 9 represent extinction trials.

Two bettas (S12 and S24) were given an extinction condition in which the target fish was removed on Blocks 79. Similar patterns of learning and extinction were observed in both subjects. Figure 5 presents the results for Subject 12.

Finally, one fish (S27) failed to learn but simply hovered near the hurdle, while his target fish showed little movement and weak displays.

\section{DISCUSSION}

Observation revealed that the reinforcement on the first 4-5 trials was a composite of display and fighting. However, on later trials, the subject betta ceased the initial display and attacked as soon as it crossed the partition. Attack and fighting have been found to be a reinforcement in other species (e.g., Myer \& White, 1965; Tellegen \& Horn, 1972). 
Recently Bronstein (1981) has challenged instrumental and operant studies of display reinforcement in bettas, holding that released and reinforced behaviors are confounded, but his argument does not appear relevant to the present results. The nine fish in the current study initiated the hurdle-crossing response without the target fish being sighted (and thus releasing a response).

Most subjects received several bites, yet they maintained the instrumental response. These results are congruent with findings indicating that a moderate level of punishment facilitated aggressive display or a related operant response in bettas (Melvin \& Anson, 1969; Melvin \& Ervey, 1973).

In general, the fish that maintained crossing bit first and more often. With reinforcement being a mirror-image/display, Baenninger (1970) found that dominant bettas performed the operant response at a much higher rate than submissive bettas.

In studies of operant performance, strength of the betta's response is generally a function of the display-eliciting properties of various reinforcing stimuli (e.g., Bols, 1977; Rhoad, Kalat, \& Klopfer, 1975). The present results certainly support such a conclusion, especially in reference to the effects of the targets' submissive display.

Research involving mirros, however, typically does not yield the submissive display. As the present data show, once the target fish displayed submissively, its reinforcing value quickly declined. Thus, to be optimally reinforcing, the target betta must be (a) not dominant, (b) evenly matched, and (c) not submissive. Long ago, Craig (1928) stated, "Even when an animal does fight, he aims, not to destroy the enemy, but only to get rid of his presence and his interference." Certainly, the present results support Craig's notion: A betta that is no longer there (extinction) or is submissive is no longer a threat, and the instrumental seeking response fades away.

Given the small scale nature of the present study, certain questions remain unanswered. There is no direct comparison here of display versus attack/display. And, because subject fish select their role in this procedure, they probably are above the median in aggressiveness. In any case, it appears that the reinforcing value of aggressive encounters in bettas depends on a delicate balance of the attributes of both combatants.

\section{REFERENCES}

BAENNINGER, R. (1970). Visual reinforcement, habituation, and social experience of Siamese fighting fish. Journal of Comparative \& Physiological Psychology, 71, 1-5.

BoLs, J. R. (1977). Display reinforcement in the Siamese fighting fish, Betta splendens: Aggressive motivation or curiosity? Journal of Comparative \& Physiological Psychology, 91, 233-234.

Bronstein, P. M. (1981). Social reinforcement in Betta splendens: A reconsideration. Journal of Comparative \& Physiological Psychology, 95, 943-950.

CraIG, W. (1928). Why do animals fight? International Journal of Ethics, 31, 264-278.

Melvin, K. B., \& Anson, J. E. (1969). Facilitative effects of punishment on aggressive behavior in the Siamese fighting fish. Psychonomic Science, 4, 89-90.

Melvin, K. B., \& ERveY, D. H. (1973). Facilitative and suppressive effects of punishment on species-typical aggressive display in Betta splendens. Journal of Comparative and Physiological Psychology, 83, 451-457.

Myer, J. S., \& White, R. T. (1965). Aggressive motivation in the rat. Animal Behavior, 13, 430-433.

Rhoad, K. D., Kalat, J. W., \& Klopfer, P. H. (1975). Aggression and avoidance by Betta splendens toward natural and artificial stimuli. Animal Learning \& Behavior, 3, 271-276.

Tellegen, A., \& HoRn, J. M. (1972). Primary aggressive motivation in three inbred strains of mice. Journal of Comparative \& Physiological Psychology, 78, 297-304.

Tномpson, T. (1963). Visual reinforcement in Siamese fighting fish. Science, 141, 55-57.

(Manuscript received for publication March 12, 1985.) 